\title{
EDITORIAL
}

For reprint orders, please contact: reprints@futuremedicine.com

\section{Single gene variants in risk and protection: a new view on the genetic etiology of Parkinson's disease}

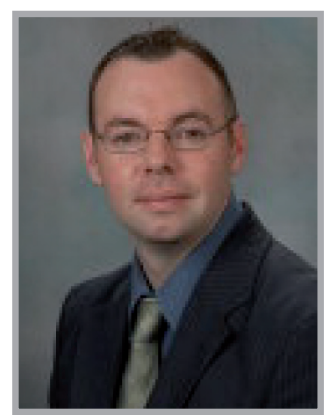

Owen A Ross*

\author{
"Originally thought of as the archetypal
} sporadic disease, Parkinson's disease has experienced a paradigm shift, with genetic insights now being the overwhelming driving force behind functional and therapeutic avenues of research."
Parkinson's disease (PD) is one of the most common neurodegenerative disorders [1]. The visibility of the movement manifestations has somewhat dictated our interpretation of the disease and has focused research on the neurological symptoms associated with the disease. However, in the last few years a renaissance has occurred, giving rise to a greater appreciation for the systemic, non-motor features of PD [2]. I draw particular attention to this, as in the original clinical description of the disease entity, James Parkinson himself noted many of these non-motor features in his landmark report 'An essay on the shaking palsy' [3]. The multisystem pathology observed in PD underlies the complexity of the mechanisms resulting in phenotypic presentation. This is reflected in the proposed pathobiology, which has so far failed to identify a single unifying pathway.

One area of PD research that has blossomed is that of genetics. Genetic findings provide the foundation for preventative and individualized forms of medicine. It is only through the discrimination of defined genomic backgrounds that we, as a field, will be truly able to tease out the independent and joint effects of environmental agents. Originally thought of as the archetypal sporadic disease, PD has experienced a paradigm shift, with genetic insights now being the overwhelming driving force behind functional and therapeutic avenues of research $[4,5]$. Up to $20 \%$ of patients with PD report a family history of parkinsonism supporting a high genetic heritability of disease [6]. Recent studies have also shown that genetic factors not only influence familial forms of parkinsonism, but also play a critical role in sporadic disease [7].

Two approaches have been used to identify genes in PD: classical familial studies and population-based association approaches. It has become clear in PD studies that age-related penetrance is influenced by genetic variation, and that the familial genes also play an important role in population-based disease risk. Evidence for this is provided by studies on two of the best established genetic determinants of susceptibility to PD: $\alpha$-synuclein $(S N C A)$ and leucine-rich repeat kinase 2 (LRRK2), which both represent a model of disease understanding $[7,8]$. These two genes contain variants that influence

*Department of Neuroscience, Mayo Clinic, Jacksonville, 4500 San Pablo Road, Jacksonville, FL 32224, USA

\footnotetext{
"The recent identification of novel genetic forms of Parkinson's disease [by nextgeneration sequencing approaches] may mark the end of traditional genetic linkage approaches in nominating genes for inherited forms of disease."
} 
disease risk in different ways and provide not only pathomechanistic insights, but also novel therapeutic avenues to follow.

SNCA point mutations were the first genetic cause of PD identified, and subsequently genomic multiplication of the entire SNCA locus was found in families with dominantly inherited PD [9,10]. This observation proposed overexpression of $S N C A$ and the $\alpha$-synuclein protein as a dose-dependent risk, which suggests knockdown as a possible treatment. Given the presence of the $\alpha$-synuclein protein in Lewy bodies, the pathologic substrate of $\mathrm{PD}$, this finding may well have implications for a substantial number of patients with idiopathic PD. The overexpression hypothesis fits with observations that common genetic variation within the $S N C A$ locus affects risk in a population of sporadic patients [8]. Indeed, a repeat polymorphism in the promoter region of $S N C A$ has been postulated to be the functional variation driving risk association [11]. The length of the Rep1 repeat is reported to alter gene expression, with the longer repeat resulting in higher expression and increased disease risk. The shorter repeat allele reflecting reduced $S N C A$ expression is associated with protection against the development of PD. This was one of the first examples of a single gene that harbors both risk and protective variations.

Genetic variation within the LRRK2 gene represents the most frequent cause of PD [7]. LRRK2-associated parkinsonism reflects many of the phenomena observed with late-onset genetic disorders, including age-related penetrance and ethnic specificity of mutation frequency. The LRRK2 G2019S mutant has been observed to cause up to $30-40 \%$ of cases of familial and sporadic patients with $\mathrm{PD}$ depending on ethnicity $[12,13]$. Carriers of LRRK2 G2019S present with a disease phenotype that is indistinguishable from typical Lewy body PD [14]. All LRRK2 mutations display a high degree of age-related penetrance; in addition a number of variants have been identified that elicit a lower penetrance risk [15-17]. Our recent studies on LRRK2 variation in large Caucasian and Asian patient-control series have demonstrated the presence of both risk and protective alleles within $L R R K 2$ [7]. In addition to the established risk factors, we identified a protective haplotype (LRRK2 N551K-R1398H$\mathrm{K} 1437 \mathrm{~K}$ ) that appears to be present in certain populations globally $[7,15]$. Given that the underlying hypothesis for $L R R K 2$-associated $\mathrm{PD}$ is a toxic gain-of-function with most proposing the putative kinase activity as the mechanism for disease, our findings suggest that we can manipulate the toxic nature of LRRK2 and perhaps tailor neuroprotective therapies for individual patients.

To date, a biomarker in PD, or lack thereof, has restricted our ability to develop and test potential disease progression-targeted therapies. The best we can offer a patient is symptom alleviation with L-3,4-dihydroxyphenylalanine replacement therapy, but this neither slows nor halts the progression of the disease. The genetic findings clearly support the idea of PD as a syndrome that is clinically and pathologically made up of intersecting pathways of disease. As we consider the Parkinson's syndrome, it becomes evident that to treat this disorder a combinational strategy must be employed utilizing multiple drugs to target multiple pathogenic pathways. By the time a patient with PD presents at the neurologist's office, between 50 and $70 \%$ of dopaminergic neurons in the substantia nigra and projections to the striatum have been lost [1]. It is likely that therapeutic intervention at this stage will do little to halt the progression of the disease. Just as preventative medicine has been employed in vascular disease with statins and antihypertensives being used to lower the risk of heart disease or stroke, we must be able to identify those at risk of preclinical PD and employ early neuroprotective approaches.

The recent identification of novel genetic forms of PD may mark the end of traditional genetic linkage approaches in nominating genes for inherited forms of disease [18-20]. The era of next-generation sequencing technologies is upon us and may hold the key to resolving some of the different forms of PD. These advances give clinicians another weapon in their diagnostic arsenal. The genomic background (profile) for patients with PD will dictate the combination therapy needed; for example, an individual may require a knockdown of $\alpha$-synuclein and a LRRK2 inhibitor, while another may only require a LRRK2 inhibitor. The combined effects of multiple common genetic risk loci such as $S N C A$, $L R R K 2$ and others will also be a major focus of genetic research as sample sizes increase and a better understanding of gene-gene interactions are developed [21]. The lessons we have learned from both common protective and risk genetic determinants suggest that this is feasible and may become the foundation for prevention and treatment. 


\section{Acknowledgements}

The author would like to thank all those who have contributed to his research, particularly the patients and families who donated DNA samples for this work.

\section{Financial \& competing interests disclosure}

$O A$ Ross is supported by the family of CE Bolch Jr and SB Bolch, the Michael J Fox Foundation, the National Institute of Neurological Disorders and Stroke R01\# NS078086. The Mayo Clinic Jacksonville (FL,

\section{References}

1 Lees AJ, Hardy J, Revesz T. Parkinson's disease. Lancet 373(9680), 2055-2066 (2009).

2 Langston JW. The Parkinson's complex: parkinsonism is just the tip of the iceberg. Ann. Neurol. 59(4), 591-596 (2006).

3 Parkinson J. An essay on the shaking palsy. 1817. J. Neuropsychiatry Clin. Neurosci. 14(2), 223-236; discussion 222 (2002).

4 Ross OA, Farrer MJ. Pathophysiology, pleiotrophy and paradigm shifts: genetic lessons from Parkinson's disease. Biochem. Soc. Trans. 33(Pt 4), 586-590 (2005).

5 Wider C, Ross OA, Wszolek ZK. Genetics of Parkinson disease and essential tremor. Curr. Opin. Neurol. 23(4), 388-393 (2010).

6 Rocca WA, Mcdonnell SK, Strain KJ et al. Familial aggregation of Parkinson's disease: the Mayo clinic family study. Ann. Neurol. 56(4), 495-502 (2004).

7 Ross OA, Soto-Ortolaza AI, Heckman MG et al. Association of LRRK2 exonic variants with susceptibility to Parkinson's disease: a case-control study. Lancet Neurol. 10(10), 898-908 (2011).

8 Ross OA, Gosal D, Stone JT et al. Familial genes in sporadic disease: common variants of $\alpha$-synuclein gene associate with Parkinson's

USA) is a Morris K Udall Parkinson's Disease Research

Center of Excellence (National Institute of Neurological Disorders and Stroke P50 \#NS072187). The author has no other relevant affiliations or financial involvement with any organization or entity with a financial interest in or financial conflict with the subject matter or materials discussed in the manuscript apart from those disclosed.

No writing assistance was utilized in the production of this manuscript.

disease. Mech. Ageing Dev. 128(5-6), 378-382 (2007).

9 Ross OA, Braithwaite AT, Skipper LM et al. Genomic investigation of $\alpha$-synuclein multiplication and parkinsonism. Ann. Neurol. 63(6), 743-750 (2008),

10 Singleton AB, Farrer M, Johnson J et al. $\alpha$-synuclein locus triplication causes Parkinson's disease. Science 302(5646), 841 (2003).

11 Maraganore DM, De Andrade M, Elbaz A et al. Collaborative analysis of $\alpha$-synuclein gene promoter variability and Parkinson disease. JAMA 296(6), 661-670 (2006).

12 Healy DG, Falchi M, O'Sullivan SS et al. Phenotype, genotype, and worldwide genetic penetrance of $L R R K 2$-associated Parkinson's disease: a case-control study. Lancet Neurol. 7(7), 583-590 (2008).

13 Hulihan MM, Ishihara-Paul L, Kachergus J et al. LRRK2 Gly2019Ser penetrance in Arab-Berber patients from Tunisia: a case-control genetic study. Lancet Neurol. 7(7), 591-594 (2008).

14 Kachergus J, Mata IF, Hulihan Met al. Identification of a novel $L R R K 2$ mutation linked to autosomal dominant parkinsonism: evidence of a common founder across European populations. Am. J. Hum. Genet. 76(4), 672-680 (2005).
15 Tan EK, Peng R, Teo YY et al. Multiple $L R R K 2$ variants modulate risk of Parkinson disease: a Chinese multicenter study. Hum. Mutat. 31(5), 561-568 (2010).

16 Di Fonzo A, Wu-Chou YH, Lu CS et al. A common missense variant in the LRRK2 gene, Gly2385Arg, associated with Parkinson's disease risk in Taiwan. Neurogenetics 7(3), 133-138 (2006).

17 Ross OA, Wu YR, Lee MC et al. Analysis of $L R R K 2 R 1628 P$ as a risk factor for Parkinson's disease. Ann. Neurol. 64(1), 88-92 (2008).

18 Vilarino-Guell C, Wider C, Ross OA et al. VPS35 mutations in Parkinson disease. Am. J. Hum. Genet. 89(1), 162-167 (2011).

19 Ross OA, Farrer MJ. Parkinson disease: Parkinson disease - moving beyond association. Nat. Rev. Neurol. 6(6), 305-307 (2010).

20 Zimprich A, Benet-Pages A, Struhal W et al. A mutation in VPS35, encoding a subunit of the retromer complex, causes late-onset Parkinson disease. Am. J. Hum. Genet. 89(1), 168-175 (2011).

21 Elbaz A, Ross OA, Ioannidis JP et al. Independent and joint effects of the MAPT and SNCA genes in Parkinson disease. Ann. Neurol. 69(5), 778-792 (2011). 